\title{
Optimized Production of Fatty Acid Ethyl Esters (FAEE) from Waste Frying Oil by Response Surface Methodology
}

\author{
Marcelo F. Ortega ${ }^{1} \cdot$ David Donoso $^{2} \cdot$ Hamza Bousbaa $^{3} \cdot$ David Bolonio $^{1} \cdot$ Rosario Ballesteros $^{2}$ (D) \\ María-Jesús García-Martínez ${ }^{1}$. Magín Lapuerta ${ }^{2} \cdot$ Laureano Canoira $^{1}$
}

Received: 27 February 2020 / Accepted: 29 June 2020 / Published online: 23 July 2020

(c) Springer Nature B.V. 2020

\begin{abstract}
In Europe, recent regulations on advanced biofuels have prompted a search for new fuel sources and the development of synthesis methods meeting the demanding specifications of the sector. However, in developing countries such as Algeria, where a significant stock of frying oil is unused, the use of diesel engines powered with waste-oil-derived biofuels must be explored. In this work, the variables related to the transesterification reaction from this frying oil with ethanol are analyzed using response surface methodology. From this analysis, only the reaction time and temperature have been determined as relevant parameters. In addition, FT-IR analysis has proven a useful tool to analyse the conversion in the transesterification reaction of waste frying oil with ethanol and is cheaper and quicker than GC-FID. This sustainable biofuel (FAEE), mixed with a diesel and pure fuel, has been physically characterized. The mixture of FAEE at $30 \%$ by volume with diesel meets the requirements demanded in standard EN 590 and can be classified as winter diesel class D. As a pure biofuel, only its high cold flow temperatures could constitute a drawback for exporting to temperate climates but not for internal consumption.
\end{abstract}

Electronic supplementary material The online version of this article (https://doi.org/10.1007/s12649-020-01149-4) contains supplementary material, which is available to authorized users.

Rosario Ballesteros

rosario.ballesteros@uclm.es

$\triangle$ Laureano Canoira

1 Department of Energy \& Fuels, ETS Ingenieros de Minas Y Energía, Universidad Politécnica de Madrid, Ríos Rosas 21, 28003 Madrid, Spain

2 Grupo de Combustibles Y Motores, ETS de Ingenieros Industriales, Universidad de Castilla-La Mancha, Avda. Camilo José Cela S/N, 13071 Ciudad Real, Spain

3 LTE Laboratory, Department of Mechanical Engineering, ENP MA-Oran, BP 1523 El Mnaouer, 31000 Oran, Algeria 


\section{Graphical Abstract}

How to recycle frying oil?

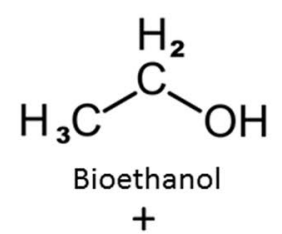

Waste frying oil
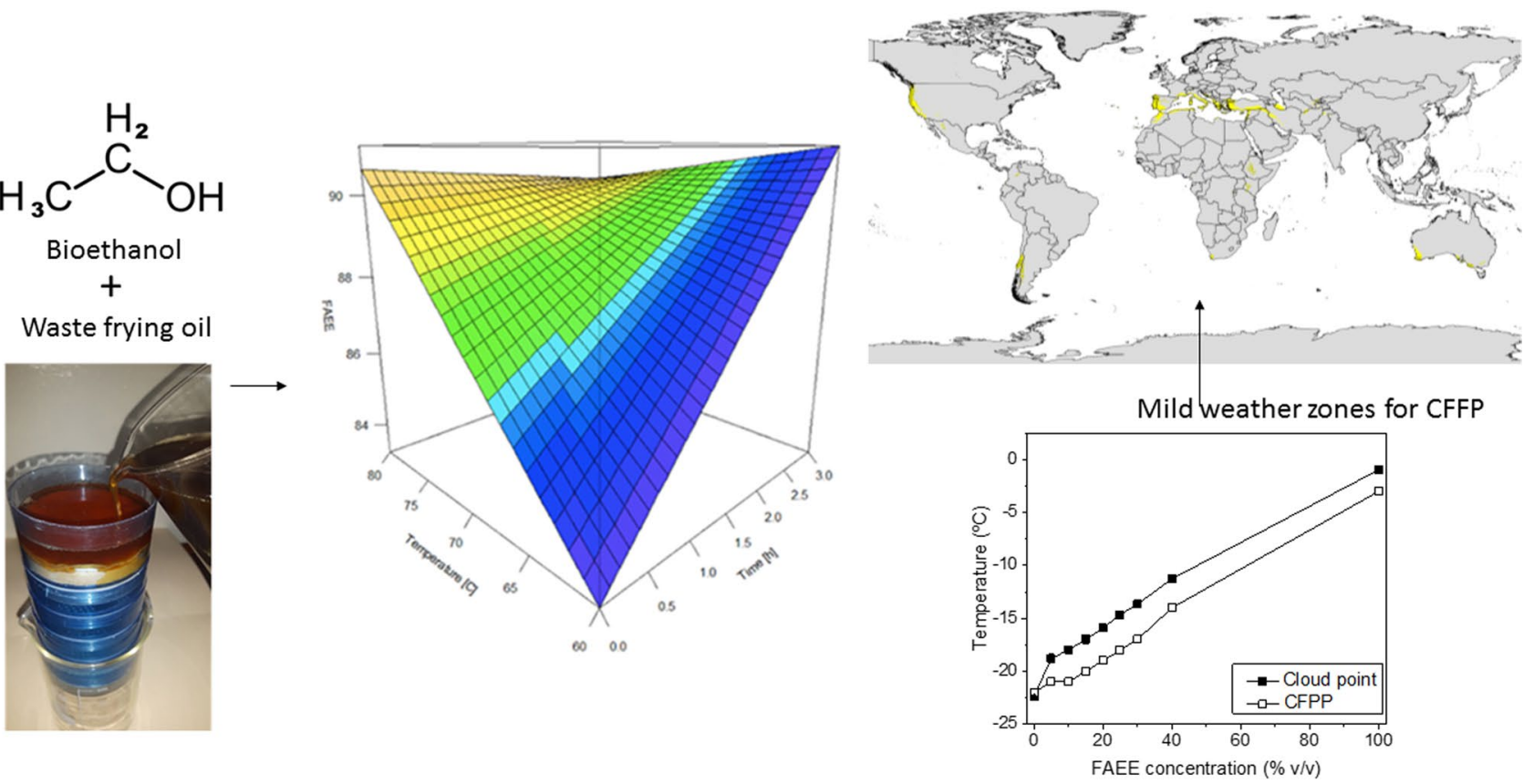

Keywords Waste frying oil · Bioethanol $\cdot$ FAEE $\cdot$ Response surface methodology $\cdot$ FT-IR spectroscopy

\section{Statement of Novelty}

With this work it can be affirmed that the most relevant variables in the ethyl transesterification of waste frying oil are the reaction time and the process temperature. Also that, the FAEE content analysis can be done with FTIR, instead more expensive and slower technique as CG-FID. And finally that the biofuel produced can be used pure in hot climates and mixed up to $30 \%$ by volume with a diesel.

\section{Introduction}

Although the European Union has issued a date for the passing out of the internal combustion engine vehicles, especially those fuelled by diesel, this fossil fuel and its biological origin counterpart biodiesel still will remain as the main fuels for road transport in many developing countries around the world in the next decades. In particular, according to sector statistics, Algeria has a catchable stock of $220 \mathrm{kt} / \mathrm{year}$ of waste frying oil, considered already as an advanced biofuel raw material [1]. Moreover, the recently approved EU Directive [2] recognizes that using waste oils for producing biodiesel has an $87 \%$ reduction of greenhouse gas emissions. Considering this, the study of the transesterification reaction of waste frying oil originated in a country outside the EU, using bioethanol as the alcohol instead of methanol has still interest for the production of biofuels to be self-consumed [3], since in this way the FAEE produced will have a fully renewable origin [4]. However, the FAEE synthesis is more challenging than the FAME production at both laboratory and industrial scales, especially the FAEE purification steps, due to the fact that FAEE, ethanol and glycerol form a triphasic system difficult to separate $[5,6]$. Thus, reaching the mandatory $96.5 \mathrm{wt} \%$ of ester content in biodiesel is easily accomplished for FAME, but not so easily for FAEE. An experimental design using response surface methodology (RSM) has been performed, trying to optimize the operating variables in the transesterification process to achieve the mandatory ester content.

The experimental designs are classical statistical models that aim to find if some determined factors have influence on a variable of interest, and, if this influence exists, to quantify it. The use of experimental design models is based on the experimentation and the analysis of results in a well-planned set of experiments. If the experimentation is carried out in a laboratory where the main causes of variability are well controlled, the experimental error will be small, and there will be small uncontrolled variations in the results of the experiments. The aim of the experimental design is to determine if 
any improvement can be achieved when a specific treatment is used. In this work, the different independent variables that influence the transesterification process have been studied, reaching as conclusion which are the most influential ones and which are their interactions. These independent variables are the molar ratio bioethanol to oil, the temperature, the amount of catalysts relative to the oil and the reaction time. The target function is the total ester content in the final biodiesel fuel. In an experimental design, the experimental results are subjected to three types of variability with the following characteristics: (i) Planned and systematic variability: this variability includes the four independent variables mentioned above. This is an important variability and it is expected that the results obtained are arranged forming groups (clusters). (ii) Typical variability, depending of the nature of the experiment. This variability is due to the random noise. It comprises the measurement errors or the operator ability to carry out the experimental measurements. This variability causes, for example, that if repeated measurements of the same sample are made in a laboratory, the second result is not equal to the first one, and even worse, the error in the third measurement cannot be predicted. This variability cannot be avoided, but if the experiments are well planned, it is possible to estimate its value. (iii) Non-planned and systematic variability: this variability is due to unknown causes not planned in advance.

The RSM method has been used to optimize biodiesel production processes [7] and in the experimental design in general [8-10]. The main advantage of RSM is that it explores the relationships between several explanatory variables and one or more response variables $[8,9]$. It can be well applied when a response or a set of responses of interest are influenced by several variables. The objective is to simultaneously optimize the levels of these variables in order to attain the best system performance [8] and, consequently, the highest saving in production costs. As a limitation of this methodology, it is important to mention that it is a local analysis. The developed response surface is invalid for regions other than the studied ranges of factors. The novelty of this work is the application of RSM to further optimize a transesterification process that is already well established in the literature, namely FAEE production from waste oils, by increasing the ester content [e.g. from 93 to $96.5 \mathrm{wt} \%$ (which is the minimum FAME content in EN 14214)]. This is a challenging task that cannot be accomplished by the classical approach of varying a parameter at a time, making necessary the use of an experimental design statistical tool. The RSM method has been employed before in analytical chemistry $[8,10]$, but only Mueanmas et al. have applied it to study the esterification step of biodiesel production [7]. Thus, the purpose of our work is to optimize the FAEE production using a RSM statistical tool, not to argue about the inherent advantages and drawbacks of biodiesel, which have been discussed in different reviews in the literature [11]. Also, the polluting effects of diesel and biodiesel on the air quality in the cities has also been well reviewed. Biodiesel production is an environmentally acceptable end use for waste frying oil that otherwise will end in the home drain without remedy [12]. Moreover, if the ethanol waste comes from fermentation, it makes the biodiesel a fully renewable biofuel, thus increasing its sustainability. Sustainable biofuels still have a wide niche in the actual fuels portfolio all over the world.

\section{Materials and Methods}

\section{Introduction}

The waste oil for this work was a blend of $95 \mathrm{vol} \%$ of soybean and 5 vol\% of corn oils, supplied by the restaurant "La poissonerie du port" in Oran (Algeria) and it was heavily used for frying fish. The temperature observed during the fish frying was in the range of 100 to $150{ }^{\circ} \mathrm{C}$. Five liters of oil sample were collected from a collecting drum in which the waste frying oil was dumped in once every day and kept at a room temperature for one day to enable settling. Two liters of this waste frying oil were heated up to $50{ }^{\circ} \mathrm{C}$ for $10 \mathrm{~min}$ to rule out the presence of water. Thereafter, the oil was filtered through a filter composed of cotton cloth, filter paper and around $1 \mathrm{~cm}$ of fine quartz sand to remove slag and impurities in a plastic container (see Figure 1S in Supplementary Material).

Sodium metal (Rhone-Poulenc, Paris, France), absolute ethanol, citric acid, $n$-heptane, medium boiling point petroleum ether and sodium chloride (Panreac, Barcelona, Spain) were used without further purification. The feedstock oil was tested for humidity by FT-IR spectroscopy in a Nicolet 6700 instrument (Fischer Scientific, USA) placing an oil drop between two sodium chloride discs (Aldrich, USA, $5.40 \mathrm{~mm}$ thick, $24.97 \mathrm{~mm}$ o.d.). The oil acidity index was determined after the standard method EN 14104.

\section{Preparation of the Sodium Ethoxide Catalyst}

Sodium metal (7.20 g, $0.313 \mathrm{~mol})$ cut in small pieces and stored under medium boiling point petroleum ether was added slowly to absolute ethanol ( $75 \mathrm{~mL}, 58.5 \mathrm{~g}, 1.272 \mathrm{~mol})$ in a $100 \mathrm{~mL}$ flat bottomed flask with stirring at $1500 \mathrm{rpm}$ and room temperature, until total dissolution of the sodium. The flask was connected to a reflux condenser cooled by running water during the addition of the sodium. The resulting sodium ethoxide solution has a concentration of $21 \mathrm{wt} \%$ and it was always stored under nitrogen after use. However, although the initial sodium ethoxide solution was only slightly yellow, it darkened with time to a dark brown 
colour (the same colour of the commercial $21 \mathrm{wt} \%$ solution bought from Acros Organics stored in a Sure-seal bottle). In this work, only the sodium ethoxide solution prepared by the authors was used in all the experiments, and the commercial solution was only bought for comparison purposes.

\section{Transesterification Procedure}

Waste frying oil $(50 \mathrm{~mL})$ and absolute ethanol $(20.64 \mathrm{~mL}$, $16.1 \mathrm{~g}, 0.35 \mathrm{~mol}$ ) were placed in a $100 \mathrm{~mL}$ flat bottomed flask connected to a reflux condenser cooled by running water, and the mixture was heated at $70{ }^{\circ} \mathrm{C}$ with stirring at $600 \mathrm{rpm}$ in a stirring plate Nahita Blue $692 / 1$. When the reaction mixture reached the $70^{\circ} \mathrm{C}$, the catalyst sodium ethoxide solution was added $(3.27 \mathrm{~mL}$ of solution at $21 \mathrm{wt} \%$, $0.687 \mathrm{~g}, 0.010 \mathrm{~mol}, 1.5 \mathrm{wt} \%$ of the oil). After $2 \mathrm{~h}$ of reaction, the stirring and heating were stopped, and the reaction mixture was transferred to a decanting funnel and left

Table 1 Fatty acid profile $\mathrm{e}^{\mathrm{a}}$ and total ester content of waste frying oil FAEE

\begin{tabular}{lrl}
\hline Fatty acid & wt\% & RSD (\%) \\
\hline $\mathrm{C}_{16: 0}$ & 12.1 & 1.6 \\
$\mathrm{C}_{18: 0}$ & 4.1 & 0.8 \\
$\mathrm{C}_{18: 1}$ & 25.9 & 0.8 \\
$\mathrm{C}_{18: 2}$ & 52.3 & 0.1 \\
$\mathrm{C}_{18: 3}$ & 5.2 & 0.3 \\
Other & 0.4 & - \\
Fatty acid & 91.7 & 0.8 \\
$\quad$ ester content & & \\
$\quad$ (wt\%) & & \\
\hline
\end{tabular}

$R S D$ relative standard deviation (\%)

${ }^{\mathrm{a}}$ Fatty acid profile has been normalized to $100 \mathrm{wt} \%$ to decant overnight. The next day, the lower G-phase was decanted and discarded, and the upper FAEE phase was distilled under reduced pressure in a rotavapor Büchi 461 (Basel, Switzerland), decanting a new G-phase formed after eliminating the excess ethanol. The crude FAEE was neutralized with $12.5 \mathrm{~mL}$ ( $25 \mathrm{vol} \%$ ) of a $1 \mathrm{wt} / \mathrm{vol} \%$ solution of citric acid, and later washed with $12.5 \mathrm{~mL}$ ( $25 \mathrm{vol} \%$ ) of a 3 $\mathrm{wt} / \mathrm{vol} \%$ solution of sodium chloride and three successive washings with distilled water. To separate the FAEE from the distilled water washings, a centrifugation step was necessary, using a centrifuge Digitor 20 of Orto-Alresa. Finally, the FAEE was dried with $8 \mathrm{wt} \%$ of $4 \AA$ molecular sieve (Probus, Barcelona, Spain) previously activated at $200{ }^{\circ} \mathrm{C}$ overnight, and the FAEE was vacuum filtered through a $45 \mu \mathrm{m}$ filter (Millipore, USA). This experimental procedure was followed exactly in all the tests of the experimental design, of course with the changes of reaction parameters temperature, time, molar ratio ethanol to oil and catalyst amount settled in the design.

\section{Chemical Analysis}

The ester profile of the FAEE was obtained by gas chromatography and flame ionization detector (GC-FID) in an equipment Hewlett-Packard 5890 series II following the standard method EN 14,103. An HP-Wax column $(30 \mathrm{~m} \times 0.32 \mathrm{~mm}$ i.d. $\times 0.15 \mu \mathrm{m})$ of crosslinked polyethylene glycol was used for separation. The following analytical conditions were used for the analysis: injector temperature, $210{ }^{\circ} \mathrm{C}$; split ratio, $70: 1$; injection volume, $1 \mu \mathrm{L}$; column flowrate (He), $1 \mathrm{~mL} / \mathrm{min}$ constant flow mode; FID temperature, $240{ }^{\circ} \mathrm{C} ; \mathrm{H}_{2}$ flowrate $40 \mathrm{~mL} / \mathrm{min}$; synthetic air flowrate, $400 \mathrm{~mL} / \mathrm{min}$; oven program, $200^{\circ} \mathrm{C}$, hold $9 \mathrm{~min}$, to $230{ }^{\circ} \mathrm{C}$ at $20^{\circ} \mathrm{C} / \mathrm{min}$, hold $10 \mathrm{~min}$; calibration standard, solution of

Table 2 Experimental design with independent variable values

\begin{tabular}{llllll}
\hline Level & Molar ratio (ethanol/oil) & Temperature $\left({ }^{\circ} \mathrm{C}\right)$ & Catalyst $(\%)$ & Time $(\mathrm{h})$ \\
\hline-1 & 6 & 65 & & 1 & 1 \\
0 & 7 & 70 & & 1.5 & 2 \\
1 & 8 & 75 & & 2 & 3 \\
\hline Run order & Std. order & Molar ratio (ethanol/oil) & Temperature $\left({ }^{\circ} \mathrm{C}\right)$ & Catalyst $(\%)$ & Time $(\mathrm{h})$ \\
\hline 1 & 8 & 8 & 75 & 2 & 1 \\
2 & 6 & 8 & 65 & 2 & 3 \\
3 & 4 & 8 & 75 & 1 & 3 \\
4 & 5 & 6 & 65 & 2 & 1 \\
5 & 2 & 8 & 65 & 1 & 1 \\
6 & 3 & 6 & 75 & 1 & 2 \\
7 & 9 & 7 & 70 & 1.5 & 3 \\
8 & 7 & 6 & 75 & 2 & 3 \\
9 & 1 & 6 & 65 & & 1 \\
\hline
\end{tabular}


methyl heptadecanoate (Aldrich, USA) in $n$-heptane ( $3 \mathrm{mg}$ / $\mathrm{mL}$ ); sample preparation, $250 \mathrm{mg}$ of sample in $10 \mathrm{~mL}$ vial with $5 \mathrm{~mL}$ of methyl heptadecanoate solution. The sample was injected in the chromatograph three times. The ester profile (Table 1) is the average of the three measurements and the relative standard deviation of the percentages shown in Table 1 is lower than $1.6 \%$. With this composition the average molecular weight of the fuel, $307.16 \mathrm{~g} / \mathrm{mol}$ and its average molecular formula, $\mathrm{C}_{19.74} \mathrm{H}_{36.57} \mathrm{O}_{2}$, have been estimated.

Fourier-transform infrared spectroscopy (FT-IR) was used to determine the FAEE content for each tests. Besides that, seven calibration samples were prepared by weight in a balance Kern 770 (accuracy $\pm 0.1 \mathrm{mg}$ ) with pure waste frying oil and the FAEE obtained as described in the experimental section, which had a total ester content of $91.7 \mathrm{wt} \%$ as analysed by GC-FID. The calibration samples were prepared by placing a small drop of the sample between two sodium chloride discs (Aldrich, USA, $5.40 \mathrm{~mm}$ thick, $24.97 \mathrm{~mm} \mathrm{o.d.)}$ and registering the infrared spectrum between 4000 and $600 \mathrm{~cm}^{-1}$ at $4 \mathrm{~cm}^{-1}$ resolution (32 scans) in a FT-IR instrument Nicolet 6700 . The absorbance of the bands at $1040 \mathrm{~cm}^{-1}$ and $1465 \mathrm{~cm}^{-1}$ was measured, integrating automatically the area under these peaks using the software Omnic v. 8.0 from Thermo Scientific. The composition of the seven standard samples, the absorbances at $1040 \mathrm{~cm}^{-1}$ and $1465 \mathrm{~cm}^{-1}$ and their ratio are shown in the Supplementary Material (Table 1S). Also, in the supplementary material, Figure $2 \mathrm{~S}$ shows the calibration curve for the absorbance ratio versus the FAEE mass fraction, including the linear correlation and the regression coefficient, and Figure $3 \mathrm{~S}$ in Supplementary Material shows the spectra used for calibration.

All the FAEE samples obtained from the experimental design were analysed by FT-IR spectroscopy in exactly the same way as the standard samples.

Table 3 Results of the experimental design by FT-IR measurements

\begin{tabular}{lll}
\hline Experiment & Absorbance ratio 1040/1465 & $\begin{array}{l}\text { FAEE con- } \\
\text { tent (wt } \%)\end{array}$ \\
\hline 1 & 0.571 & 88.4 \\
2 & 0.588 & 91.1 \\
3 & 0.585 & 90.6 \\
4 & 0.563 & 87.2 \\
5 & 0.561 & 87.0 \\
6 & 0.584 & 90.4 \\
7 & 0.572 & 88.6 \\
8 & 0.583 & 90.3 \\
9 & 0.587 & 90.9 \\
\hline
\end{tabular}

\section{Experimental Design}

Four independent variables at three different levels have been considered in the experimental design as indicated in Table 2, molar ratio ethanol to oil, temperature, catalyst amount and reaction time. $\mathrm{R}$ software version 3.5.3 [13] was used to analyse the effect of these variables on the only dependant variable, the total FAAE content of the biodiesel. Only 9 experiments of 27 were necessary to ascertain the results of this experimental design. Table $2 \mathrm{~S}$ (in supplementary information) summarizes the amounts of waste frying oil, (50 mL in all tests), absolute ethanol and sodium ethoxide catalyst for the nine experiments. All the experiments were carried out exactly as indicated in the "Transesterification Procedure" section, but with the amounts indicated in Table 2S.

\section{Physical and Cold Flow Properties}

Diesel without any oxygen content, known as first fill diesel, was supplied by Repsol (Spain) and mixed with FAEE at 5, $10,15,20,30$ and $40 \%$ in volume. Density was measured based on standard EN 3675, using a $10 \mathrm{~mL}$ glass pycnometer and a climate chamber Ineltec (used to set the temperature and humidity of the sample to $15{ }^{\circ} \mathrm{C}$ and $45 \%$, respectively). Higher heating value was measured according to standard method EN 51,123 in a Parr 1351 calorimetric pump. Viscosity of the blends was measured based on standard EN 3104 using a Froton viscosimeter 150 series and a thermal bath Tamson Zoetermeer-Holland TV 2000 to keep the samples at $40{ }^{\circ} \mathrm{C}$ during the test. Wear scar diameter was measured to quantify the lubricity of the blends, based on standard EN 12156-1, using a High Frequency Reciprocating Rig (HFRR) from PCS Instruments and a microscope Optika SRZ-1 coupled to Motical 2500 digital camera. Cloud point, based on standard test method EN 3015 was measured in an automated cloud point analyzer CPP 5Gs from PAC instruments. Cold filter plugging point (CFPP) was measured in the FPP 5Gs analyzer from PAC instruments, according to standard EN 116. All the fuels specifications, standard methods and measurement devices are specified in Table 3S.

\section{Results and Discussion}

The yield of the biodiesel production (ratio of volume of FAEE produced to that of used oil) was around $92 \%$. Table 3 summarizes the results of the experiments carried out in this work with FT-IR. In particular, the absorbance ratio at 1040 and $1465 \mathrm{~cm}^{-1}$ and the FAEE content are shown. The FT-IR analysis has proven itself a useful tool to analyse the conversion in the transesterification reaction of animal fat with methanol to yield FAME [14]. In that work, the infrared 
Table 4 Statistical adjustment parameters for Eq. 1

\begin{tabular}{lllrl}
\hline Column 1 & Estimate & $\mathrm{SE}$ & $\mathrm{t}$ value & $\operatorname{Pr}(>|\mathrm{t}|)$ \\
\hline (Intercept) & 61 & 8.36224 & 7.295 & 0.000758 \\
Temp & 0.37 & 0.11916 & 3.105 & 0.026702 \\
$\mathrm{~T}$ & 11.05 & 3.73992 & 2.955 & 0.031716 \\
temp: $\mathrm{t}$ & -0.14 & 0.05329 & -2.627 & 0.046699 \\
\hline
\end{tabular}

bands chosen for measurement were 1436 and $1465 \mathrm{~cm}^{-1}$ and their ratio, corresponding to the deformation vibrations of $\mathrm{CH}_{3}$ and $\mathrm{CH}_{2}$ groups respectively, the first one increasing when the triacylglycerides are converted to FAME while the second one remaining practically constant. In the present study, the band at $1040 \mathrm{~cm}^{-1}$ corresponds to the stretching vibration of the $\mathrm{C}-\mathrm{O}$ bond in the $-\mathrm{OCH}_{2}-\mathrm{CH}_{3}$ groups, whereas the band at $1465 \mathrm{~cm}^{-1}$ has the same meaning than in the previous work, that is, the deformation vibration frequency of the $\mathrm{CH}_{2}$ groups. Unfortunately, in the present study, the ethanol in the G-phase interferes in the absorbance of the band at $1040 \mathrm{~cm}^{-1}$ making necessary the full purification process for all the samples. In the case of FAME there was any interference of the G-phase on any of the selected bands at 1436 and $1465 \mathrm{~cm}^{-1}$ and thus the ester conversion could be measured without any purification of the samples [14]. In any case, FT-IR analysis is cheaper and quicker than GC-FID for the determination of the ester content in transesterification experiments. However, two of the experiments (2 and 9, Table 3) in the design gave results with close FAEE content than the highest calibration point of the FT-IR calibration plot in Figure 2S. Thus, we considered necessary to carry out GC-FID analysis at least in one of these two samples to check the accuracy of the FT-IR analysis. The result of this experiment 9 by GC-FID was 89.2 wt $\%$ FAEE content, whereas the FT-IR result was $90.9 \mathrm{wt} \%$, the difference
Table 5 Confirmatory experiments results

\begin{tabular}{lcc}
\hline Experiment & FT-IR results & GC-FID results \\
\hline 1 & 94.3 & 93.4 \\
2 & 93.5 & 99.5 \\
Mean & 93.9 & 96.5 \\
SD & 0.40 & 3.05 \\
\hline
\end{tabular}

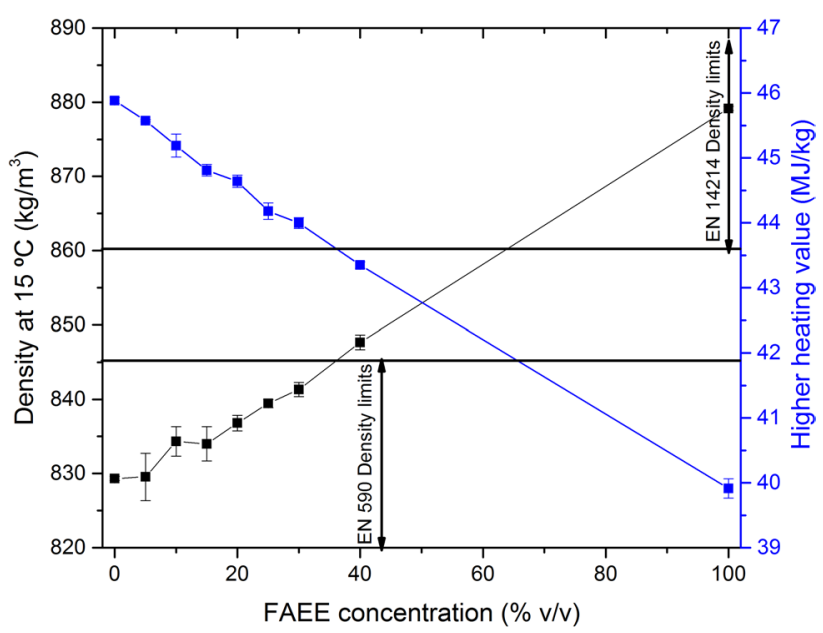

Fig. 2 Density and higher heating value for FAEE and diesel mixtures

is $1.7 \%$ that we consider acceptable taking into account that the standard deviation of the GC-FID measurements is $1.6 \%$, of the same magnitude order [15].

The R statistical software has been used to evaluate the influence of the four independent variables and their interactions on the FAEE content. After discarding some models, the most influential variables are the temperature and the reaction time, and their interaction. Table 4 shows the statistical parameters, which support the previous statement,
Fig. 1 a RSM with the most influential independent parameters and the dependant variable (FAEE content in wt \%). b Comparison between the FAEE content obtained during the tests and the FAEE content using Eq. 1
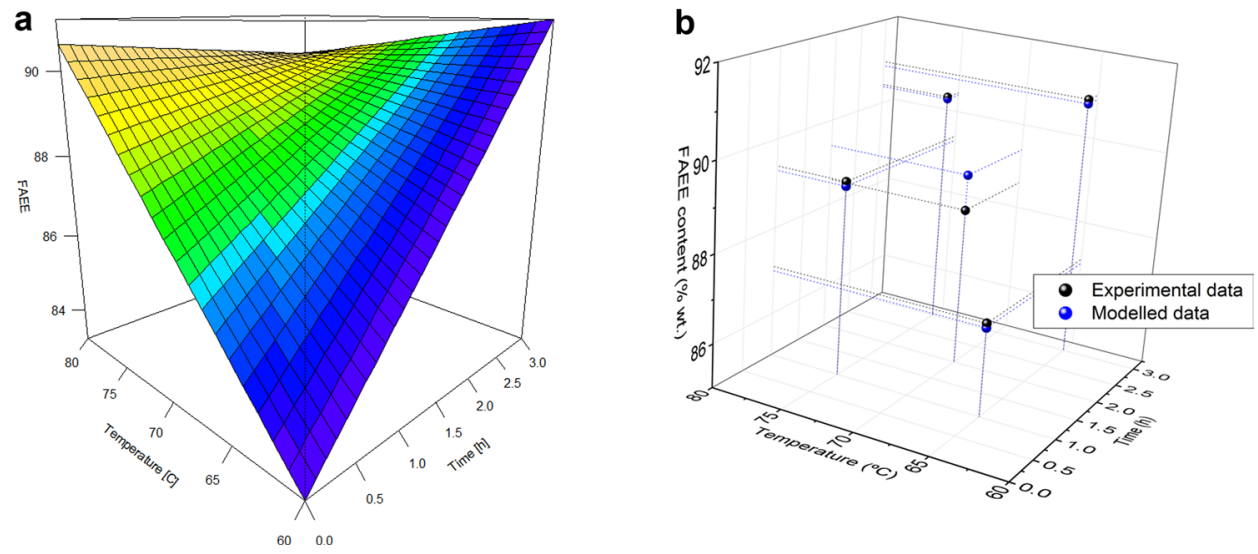

and Eq. 1 relates them: 


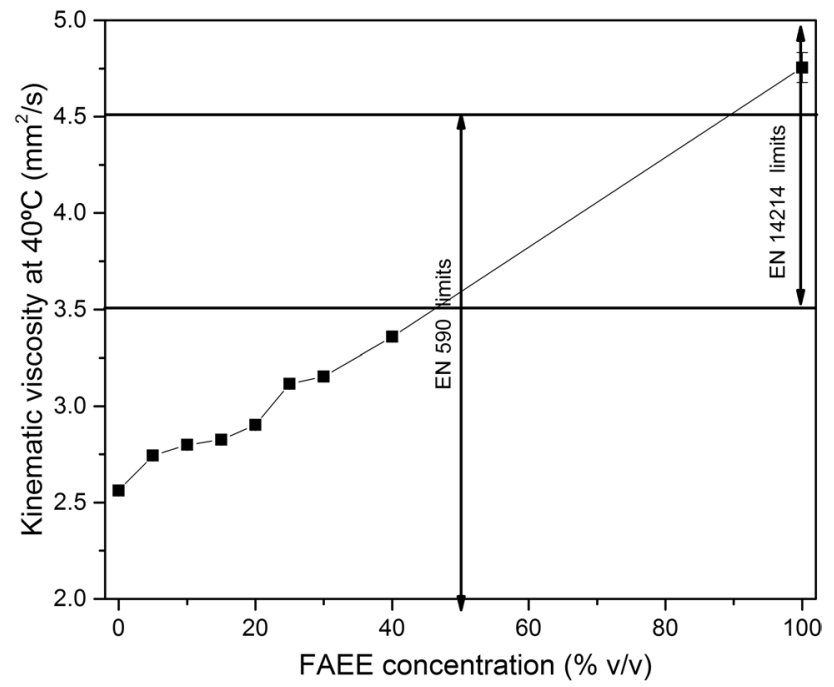

Fig. 3 Kinematic viscosity for FAEE and diesel mixtures

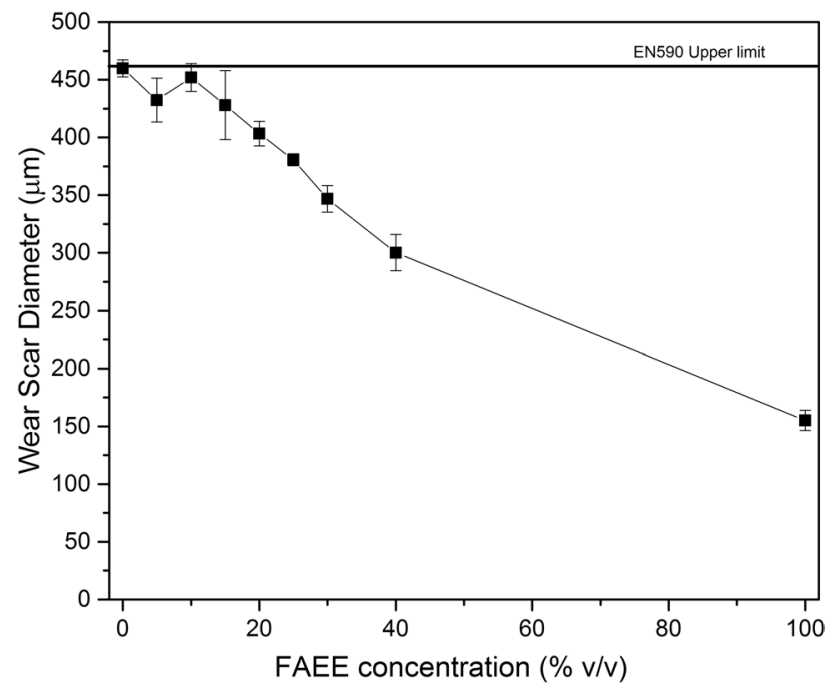

Fig. 4 Wear scar diameter for FAEE and diesel mixtures

FAEE content $(\mathrm{wt} \%)=61+0.37 \times T+11.05 \times t-0.14 \times t \times T$,

where $t$ is the reaction time (h) and $T$ is the temperature $\left({ }^{\circ} \mathrm{C}\right)$. Figure 1a shows these results in a graphical 3D form, where the maximum FAAE yield is obtained at the longest time, $3 \mathrm{~h}$, and the lowest temperature, $60^{\circ} \mathrm{C}$. These results agree well with the theory, since the transesterification is an equilibrium reaction and the highest time favours the yield, whereas the lowest temperature implies that a bigger amount of ethanol is present in the liquid phase to react with the oil. At higher temperature, more ethanol is in the vapour phase and it is less available to react with the oil. Regarding the other two independent variables, molar ratio ethanol to oil

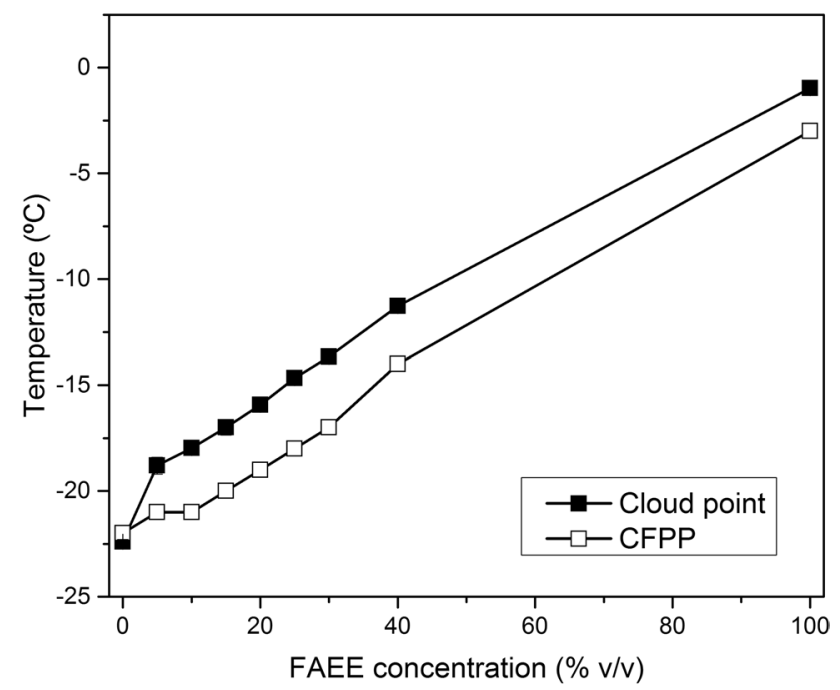

Fig. 5 Cloud and cold filter plugging points of the FAEE and diesel mixtures

and catalyst amount, they have been optimized in previous works and their increase would not report any additional yield benefit.

Under this assumption, two confirmatory experiments have been carried out in these optimized conditions, keeping the non-influential variables in the minimum value to save energy and money, that is, $3 \mathrm{~h}$ of reaction time, $60{ }^{\circ} \mathrm{C}$ of temperature, $1 \mathrm{wt} \%$ of catalyst amount and 6:1 of molar ratio ethanol to oil. The results of these two confirmatory experiments have been analysed by FT-IR and GC-FID and are summarized in Table 5. It is noticeable the mean yield obtained by GC-FID (the standard method of analysis), 96.5 $\mathrm{wt} \%$, the minimum required in the EN 14214 standard for FAME biodiesel (there is still no value required for FAEE). In any case, this ester content obtained is very high compared with the literature $[4,16](99.5 \mathrm{wt} \%$ in one of the two confirmatory experiments), so the main conclusion of this is that the optimization by RSM has been successful.

Figure $1 \mathrm{~b}$ shows the concordance between experimental FAEE content and that obtained with the proposed model Eq. 1. Figures 2, 3, 4 and 5 represent some of the most relevant physical properties of FAEE and diesel mixtures. The mixture with $30 \%$ FAEE would meet all the required properties according to EN 590 and could be included in the winter diesel class D classification with CFPP of $-10^{\circ}$ C (for "temperate" climatic zones EN 590 standard defines six classes from A to F). The pure FAEE has a perfectly suited behaviour (with respect to its cold flow properties) for the usual climatic conditions in a Mediterranean climate such as the Algerian climate, which is consistent with its fatty acid profile.

Although FAEE does not have specific standards yet, waste frying oil FAEE should fulfill all the measured properties set 
by standard EN 14214, except the oxidative stability ( $2.38 \mathrm{~h}$ : induction time), which would require the use of antioxidant additives [16]. This situation is common with biodiesel of waste frying oil, since the oil has been subjected to several cycles of heating-cooling, and this affects negatively the oxidative stability.

\section{Conclusions}

The waste oil from a fish frying restaurant in Oran (Algeria) has been transesterified with ethanol, and the reaction variables have been studied using an experimental design based on RSM. This statistical study has shown that the two most influential variables on the process are the reaction time and the temperature, and the interaction term of both. Using the optimized value of $3 \mathrm{~h}$ reaction time and $60^{\circ} \mathrm{C}$ of temperature, while maintaining the other two independent variables at the minimum values of 6:1 molar ratio ethanol to oil and $1 \mathrm{wt} \%$ sodium ethoxide catalyst to save resources, a mean value of $96.5 \mathrm{wt} \%$ FAEE content in the biodiesel has been reached. This is an excellent result, since FAEE production is more challenging than FAME production. The power of this statistical tool to obtain improvements in well-known process has been demonstrated. Finally, the FAEE content obtained has been analysed by FT-IR spectroscopy, showing good agreement with the standard method by GC-FID.

Once demonstrated the technical viability of the FAEE biodiesel production from this waste frying oil, the economic viability of using this waste in Algeria will be studied.

Acknowledgements We wish to thank the graduate students Alejandro Ferrero (UPM) and Miguel Felguera (UCLM) for its technical contribution to this work, and to dedicate this paper to the memory of the late Professor Ramón Alcántara, who died last March 26th, 2020, victim of COVID-19.

\section{References}

1. Singh, D., et al.: A review on feedstocks, production processes, and yield for different generations of biodiesel. Fuel 262, 116553 (2020)

2. Official Journal of the European Union. Directive (EU) 2018/2001 of the European parliament and of the council of 11 December
2018 on the promotion of the use of energy from renewable sources (recast version). D. Union Eur. 2018, 128 (2018)

3. Canoira, L., et al.: Biodiesel from waste olive oil: transesterification kinetics, exhaust emissions and fuel consumption. Sustain. Food Water (2009). https://doi.org/10.1007/978-90-481-3043-6_7

4. Bolonio, D., et al.: Fatty acid ethyl esters (FAEEs) obtained from grapeseed oil: a fully renewable biofuel. Renew. Energy 132, 278-283 (2019)

5. Follegatti-Romero, L.A., Oliveira, M.B., Batista, F.R., Batista, E.A., Coutinho, J.A., Meirelles, A.J.: Liquid-liquid equilibria for ternary systems containing ethyl esters, ethanol and glycerol at 323.15 and 353.15 K. Fuel 94, 386-394 (2012)

6. Rostami, M., Raeissi, S., Mahmoudi, M., Nowroozi, M.: Liquidliquid phase equilibria of systems of palm and soya biodiesels: experimental and modelling. Ind. Eng. Chem. Res. 51, 8302-8307 (2012)

7. Mueanmas, C., Nikhom, R., Kaew-On, J., Prasertsit, K.: Statistical optimization for esterification of waste coffee grounds oil using response surface methodology. Energy Procedia 138, 235-240 (2017)

8. Bezerra, M.A., Santelli, R.E., Oliveira, E.P., Villar, L.S., Escaleira, L.A.: Response surface methodology (RSM) as a tool for optimization in analytical chemistry. Talanta 76, 965-977 (2008)

9. Myers, R.H.: Response Surface Methodology Process and Product Optimization Using Designed Experiments (Wiley, Hoboken, 2016)

10. Hanrahan, G., Lu, K.: Application of factorial and response surface methodology in modern experimental design and optimization. Crit. Rev. Anal. Chem. 36, 141-151 (2006)

11. Sajjadi, B., Raman, A.A.A., Arandiyan, H.: A comprehensive review on properties of edible and non-edible vegetable oil-based biodiesel: composition, specifications and prediction models. Renew. Sustain. Energy Rev. 63, 62-92 (2016)

12. Araujo, V.K.W.S., Hamacher, S., Scavarda, L.F.: Economic assessment of biodiesel production from waste frying oils. Bioresour. Technol. 101, 4415-4422 (2010)

13. R Core Team. R: A Language and Environment for Statistical Computing [online], Vienna, Austria, 2019. https://www.r-proje ct.org/

14. Canoira, L., et al.: Biodiesel from low-grade animal fat: production process assessment and biodiesel properties characterization. Ind. Eng. Chem. Res. 47, 7997-8004 (2008)

15. Singh, D., et al.: Response factor correction for estimation of ester content in biodiesel. Chromatographia 77, 165-169 (2014)

16. Schober, S., Mittelbach, M.: The impact of antioxidants on biodiesel oxidation stability. Eur. J. Lipid Sci. Technol. 106, 382-389 (2004)

Publisher's Note Springer Nature remains neutral with regard to jurisdictional claims in published maps and institutional affiliations. 